OPEN ACCESS

Edited by: Cleoputri Yusainy,

University of Brawijaya, Indonesia

Reviewed by:

Sonia Lippke,

Jacobs University Bremen, Germany

Pradeep Nair

Central University of Himachal

Pradesh, India

Barbel Knauper,

McGill University, Canada

${ }^{*}$ Correspondence:

Qin Xu

qinxu@njmu.edu.cn

Specialty section: This article was submitted to

Health Psychology,

a section of the journal

Frontiers in Psychology

Received: 06 May 2021 Accepted: 06 August 2021

Published: 27 August 2021

Citation:

Zhao K, Xu X, Zhu H and Xu Q (2021) Compensatory Belief in Health

Behavior Management: A Concept Analysis. Front. Psychol. 12:705991.

doi: 10.3389/fpsyg.2021.705991

\section{Compensatory Belief in Health Behavior Management: A Concept Analysis}

\author{
Kang Zhao', Xinyi Xu' ${ }^{2}$, Hanfei Zhu ${ }^{1}$ and Qin $X u^{1 *}$ \\ ${ }^{1}$ School of Nursing, Nanjing Medical University, Nanjing, China, ${ }^{2}$ Faculty of Health, Queensland University of Technology, \\ Brisbane, QLD, Australia
}

Purpose: This study aimed to identify the exact definition of the concept of compensatory belief (CB) and to help clinicians and caregivers to distinguish patients who tend to form such beliefs.

Methods: This study is a conceptual analysis based on the strategy of Walker and Avant (2014). We retrieved studies from existing literature using databases such as PubMed, CINAHL, Wiley, and Web of Science, and extracted information from the results. No date limitations were applied.

Results: A total of 35 articles were sourced for data extraction. The identified attributes of CB were as follows: cognitive coping strategy, pleasure without guilt, compensatory behaviors, automatic motivated self-regulatory process, and implicit cognition. The observed antecedents were: failure to resist desire, reluctance, a conflicting motivational state, seeking appropriate balance, and self-image maintenance. The consequences of $\mathrm{CB}$ were lower health-related intentions, justification of unhealthy choices, relief from cognitive dissonance, continued existence of conflict feeling, and poor long-term health.

Conclusion: Compensatory belief stems from motivational dissonance or confliction. Despite causing feelings of pleasure and relief, it can negatively impact long-term health. Although CB is crucial to establish healthy behaviors, it is easily ignored in medical work.

Keywords: behavior management, compensatory belief, concept analysis, health behavior, health psychology

\section{INTRODUCTION}

Since the 21st century, researchers have been studying the impact of behavior on health outcomes. Activities and lifestyle factors such as smoking, overeating, and lack of exercise lead to an increased incidence of obesity and other chronic diseases (McGinnis and Foege, 1993), bringing about challenges to medical work. Consequently, people try to adopt a healthy lifestyle, hoping to reduce the occurrence of negative outcomes (Pinel et al., 2000). However, maintaining a healthy lifestyle proves difficult. Several studies on weight management have exemplified this-according to the National Institute of Health Technology, most dieters regained the weight they initially lost within 5 years, and half of the participants quitted exercise within 6 months (NIH, 1992, 1993). Why do people have difficulty persevering in their healthy behavioral choices and what is their reason to quit? 
Before the concept of compensatory belief (CB) was proposed, most health-related research studies assumed that healthy behavior choices are generated by rational assessments (Schachter, 1982; Schifter and Ajzen, 1985), and few studies took into account the motivational factors (Hart, 1993; Blanton and Gerrard, 1997). Knäuper et al. (2004) focused on the motivational factors. They put forward that cognitive dissonance occurs when the pleasure of engaging in an indulgent behavior conflicts with the potential adverse health effects, and that the resolution of this dissonance requires a process of self-regulation. There are three different situations of cognitive dissonance and their corresponding mitigation strategies. First, in the case of a high sense of self-efficacy or a low degree of temptation, people resist this desire. Second, when the desire is very strong and becomes hard to control, people adjust their risk assessment of the behavior and conform to it. Third, in the cases where the desire for behavior is medium, a contradictory belief will be activated, which Knäuper et al. termed "compensatory health belief" (CHB), also abbreviated as "compensatory belief" (CB). In this scenario, individuals consider that subsequent healthy behaviors can compensate for the adverse effects of indulging in unhealthy activities. The nature of $\mathrm{CB}$ can be well explained by the following example (Hart, 1993). On the one hand, in the face of a delectable cake, one may know the dessert itself contains a huge amount of saturated fats, cholesterol, and sugar, which is harmful to our well-being. On the other hand, one has the desire to enjoy the cake and imagines how delicious it must taste. These two conflicting perceptions lead to tangled and contradictory feelings that make one think: "it is fine to eat this cake since I will work out later to burn extra calories." In other words, one believes physical exercise can compensate for the negative effects of unhealthy foods. One uses CB to solve this "guilty pleasure" dilemma and to defend unhealthy choices. Therefore, it is precisely $\mathrm{CB}$, a concept brought to light by Knäuper et al., that complicates maintaining a healthy lifestyle.

The significance of $\mathrm{CB}$ in health behavior management has been recognized during the past two decades. Rabiau et al. (2006) introduced a model to explain the action mechanism of $\mathrm{CB}$. The model was later tested in various empirical studies, including their study on medication adherence in adolescent patients with diabetes (Rabiau et al., 2009). The study reported that emphasizing the existence of CB in the education of blood glucose monitoring and correcting their wrong ideas improved the therapeutic adherence of these patients. In addition, Radtke et al. (2014) investigated smoking-related CB under the behavior change model and improved a smoking-specific CB scale. Verger et al. (2018) studied CB in the context of influenza prevention and discovered people believe that avoiding exposure or resorting to curative treatments compensates for vaccination, which is essentially a CB. Recently, under the influence of multiple health behavior change (MHBC) vision of intervention, $\mathrm{CB}$ has become increasingly relevant. The rationale of $\mathrm{MHBC}$ consists of promoting various beneficial behaviors concurrently or in an orderly manner, within a specified period of time (Prochaska and Prochaska, 2011). Control CB can maintain multiple behavioral interventions simultaneously. Research on $\mathrm{CB}$ will help us to realize $\mathrm{MHBC}$ in medical work.
Although CB is fundamental to health behavior management, its definition remains to be heterogeneous across different studies. Only one systematic review has been written on compensatory behaviors (Buckley et al., 2019). Furthermore, most previous studies focused solely on the behaviors of concern, none have summarized the commonalities of CB among different health-related behaviors, some studies even gave controversial results (Garner et al., 2014; Sim and Cheon, 2019). Moreover, some concepts or phrases exist that have similar meanings to that of CB [e.g., moral licensing (Kouchaki, 2011) or irrational health belief (IHB) (Christensen et al., 1999)], which are likely to cause confusion. The present concept analysis was aimed at addressing these issues. By analyzing the concept of CB in this study, we hoped to gain an in-depth comprehension of its components and support the development of theories. Such understanding can help us to identify the existence of $\mathrm{CB}$ in patients and to learn how to overcome it.

\section{METHODS}

\section{Concept Selection}

In the field of health behavior, promoting the development of healthy behaviors or the avoidance of unhealthy ones is undoubtedly challenging. Although CB is considered to be a key variable that may influence this process (Rabiau et al., 2006), the lack of a uniform definition makes it difficult to distinguish CB from other similar concepts. Moreover, the methods used to evaluate this concept need to be improved (Kaklamanou et al., 2013). Since further conceptualization of CB is required, we selected this concept for analysis.

\section{Conceptual Analysis Process}

In the present study, we employed a recognized method to conceptualize $\mathrm{CB}$ in the context of health behavior management (Walker and Avant, 2014). Table 1 shows the eight steps of this method.

\section{Literature Search Strategy}

A systematic retrieval of electronic databases including PubMed, CINAHL, Wiley, and Web of Science was conducted on June 30, 2021. We used "compensatory belief" and "health behaviors" as search keywords to retrieve relevant literature and bibliography.

TABLE 1 | The eight stages of the concept analysis method conceived by Walker and Avant.

\begin{tabular}{lr}
\hline Steps in order & \multicolumn{1}{c}{ Specific content } \\
\hline Step 1 & The selection of a concept \\
Step 2 & The determination of the analysis purpose \\
Step 3 & The identification of all possible uses of the concept \\
Step 4 & The creation of the defining attributes \\
Step 5 & The identification of a model case \\
Step 6 & The identification of borderline, related, and contrary cases \\
Step 7 & The identification of antecedents and consequences \\
Step 8 & The definition of empirical referents
\end{tabular}




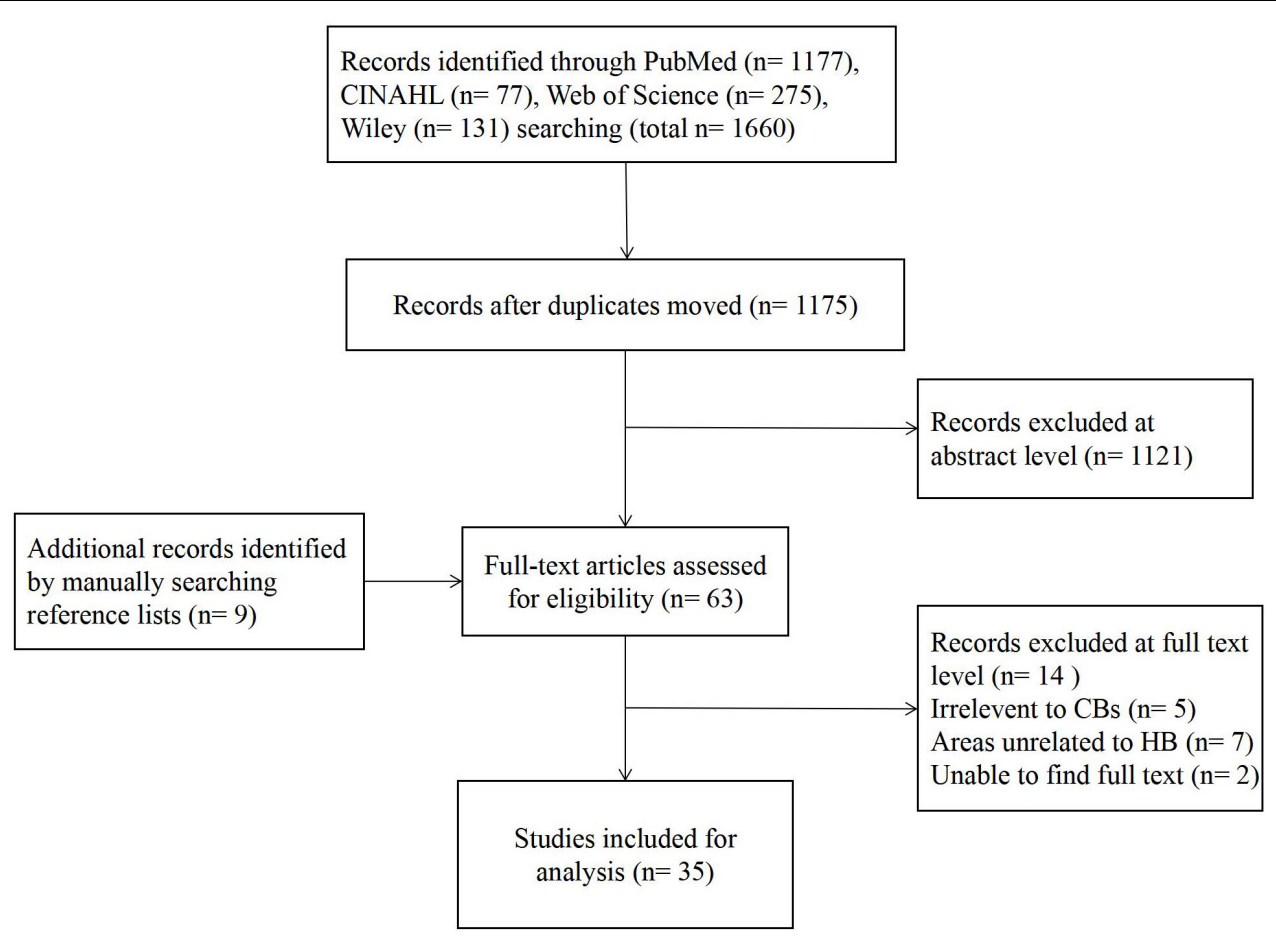

FIGURE 1 | Flowchart of the study selection process of the concept analysis.

We did not search for synonyms such as "moral licensing" and "compensatory green belief" because they are less commonly used in studies of health-related behaviors (although these are mentioned later in the related concepts section). No date limitations were applied to the search protocol. All the studies published in English focused on $\mathrm{CB}$ in the field of health behavior management were included. Of the original 1,660 studies that were found (Figure 1), 1,175 studies remained after excluding duplicates. Based on a title assessment, we also excluded irrelevant research, book reviews, letters to the editor, and studies published in a language other than English. Next, we thoroughly read the abstracts of the remaining studies and only included specific studies in the final analysis. The inclusion criteria consisted of at least one of the following items: definitions, contributing factors, attributes, antecedents, consequences, and/or method for CB measurement. The above information was extracted for subsequent analysis.

\section{RESULTS}

\section{Literature Included}

Based on the aforementioned inclusion and exclusion criteria, 35 studies were taken into account for the final analysis, including 26 quantitative studies, 4 qualitative studies, 4 literature reviews, and 1 multiple methods study. The dates of publication range from 2004 to 2021 . The studies were conducted in 12 countries, mainly distributed in Europe and North America. Study details are shown in Table 2.

\section{Utilization of CB in the Context of Health Behaviors}

In the first study (Knäuper et al., 2004) on CB, the concept was defined as a conviction that engaging in healthy behaviors can compensate for the harmful effects of previous unhealthy behaviors. Later, scholars found that CB is related to behavioral intention, self-efficacy, and risk perception (Kronick et al., 2011; Garner et al., 2014). Then, research on CB gradually began to be combined with theoretical models such as the health action process approach (HAPA) (Fleig et al., 2015) and the compensatory carry-over action model (CCAM) (Lippke, 2014), in order to systematically explore the relationship between $\mathrm{CB}$ and other variables.

The abovementioned studies mainly focused on the implementation of unhealthy behaviors mediated by $\mathrm{CB}$. Other studies, more oriented toward the anticipatory use of $\mathrm{CB}$, have investigated people applying $\mathrm{CB}$ as a reason not to perform certain behaviors, such as physical exercise, glucose testing, and vaccination (Rabiau et al., 2009; Ernsting et al., 2013; Poelman et al., 2013). Besides, reports on the use of CB became more diversified, and more specific scales to measure $\mathrm{CB}$ were gradually produced as well. Some scholars have coined other terms to describe $\mathrm{CB}$, such as "licensing" and "compensatory cognition" (Dohle and Hofmann, 2019; Lippke et al., 2021). These advances led to the discovery of other causes for $\mathrm{CB}$, such as self-image maintenance and seeking appropriate balance (Dohle and Hofmann, 2019).

In recent years, researchers have been more attentive to the nuances of this concept in different situations. Many studies 
have explored the relationship between $\mathrm{CB}$ and behavioral intention and self-efficacy by classifying patients according to the level of cognitive risk or behavioral stage (Radtke et al., 2014; Forestier et al., 2020). This allowed future interventions and management of $\mathrm{CB}$ to be more personalized. Recent research has also attempted to examine $\mathrm{CB}$ in breastfeeding and parentchild relationships (Neter and Bagants, 2020; Law et al., 2021), indicating that this concept is increasingly gaining recognition in other behavioral studies. Figure 2 shows a timeline depicting the key changes in the development of CB in the past two decades.

\section{Related Concepts}

Related concepts are terms close to the concept studied, but can be distinguished from the original concept by further analysis. We drew a Venn diagram to reflect the relationship between CB and the related concepts introduced in this review (Figure 3).

We uniformly called "compensatory belief" as "compensatory health belief" in this figure to differentiate them from other related concepts and to emphasize the health area of concern.

\section{Food and Alcohol Disturbance}

The concept "food and alcohol disturbance" (also known as drunkorexia) can be interchangeably used with the concept of CB. Food and alcohol disturbance (Choquette et al., 2018) is a type of dissonance activated when one reduces food intake for alcohol drinking to maximize drunkenness and counteract the calories of alcohol. In fact, food and alcohol disturbance is one of the dimensions in $\mathrm{CB}$, and $\mathrm{CB}$ may also relate to other problem behaviors and psychological disorders.

\section{Irrational Health Belief}

Certain concepts could be easily confused with CB. Irrational health belief, which was first employed by Christensen et al. (1999), is used to reflect negative patterns of health behavior as well as health-related cognitive distortions. For example, an individual who considers the advice of their physician unnecessary may think: "this piece of advice was not useful when I had disease X; therefore, it is not useful for any other condition." The main difference between IHB and CB is that the former just arises from outcome evaluation, while the latter is generated from conflicting motivational behaviors. In addition, IHB reflects the attributions concerning health events, whereas $\mathrm{CB}$ is related to self-regulation of health-related behavior.

\section{Moral Licensing}

Moral licensing refers to the phenomenon where individuals allow themselves to engage in morally ambiguous or immoral behavior because of past moral or socially acceptable behavior (Monin and Miller, 2001). For example, people who feel good after refuting sexist and racist comments are more likely to make discriminatory decisions. The concept of $\mathrm{CB}$ actually falls within the scope of moral licensing. However, moral licensing covers a wider range of fields and is mainly used to study social, economic, and managerial issues (Hofmann et al., 2014). Therefore, CB is not equivalent to moral licensing.

\section{Compensatory Green Belief}

Although health is the main focus of this study, CB exists in other fields as well. Compensatory green belief is a concept used in the field of environmental management (Sörqvist and Langeborg, 2019). It is frequently used to explain why people continue to damage the environment even though they are simultaneously trying to restore the environment and ecosystems. Compensatory green belief, which is also a particular type of moral licensing, can reduce the sense of guilt caused by the negative impact of detrimental behaviors on the environment.

\section{Defining Attributes}

The key component of concept analysis is the identification of the most relevant attributes with the concept, which provides researchers with a deeper understanding. The attributes contribute to distinguishing the concept under study from similar or related concepts. The most commonly defined attributes of $\mathrm{CB}$ include cognitive coping strategy, pleasure without guilt, compensatory behaviors, automatic motivated self-regulatory process, and implicit cognition.

\section{Cognitive Coping Strategy}

Cognitive coping strategy refers to strategies that reduce cognitive dissonance by changing the attitude of an individual or adding certain reasons. When individuals are faced with temptations, there is an inconsistency between their desires and their understandings of the adverse effects of temptations, leading to cognitive dissonance. This dissonance includes fear of disease due to unhealthy behaviors, collision with self-perceptions (such as "I am a healthy person"), and discrepancy with self-expectations (such as successfully quitting smoking) (de Nooijer et al., 2009; Forestier et al., 2020). The process of solving cognitive dissonance by generating $\mathrm{CB}$ is called a cognitive coping strategy (Miquelon et al., 2012).

\section{Pleasure Without Guilt}

Individuals tend to feel guilty when they surrender to temptation. People who pursue health goals will thus be filled with negative emotions, including feeling conscience-stricken and self-denial, while enjoying the happiness triggered by unhealthy behavior (Glock et al., 2013; Matley and Davies, 2018). CB emerges at this moment as a perfect excuse for those who feel guilty to engage in pleasant behavior. This belief allows individuals to connive their unhealthy behavior without feeling uncomfortable; hence, they no longer pay attention to the negative effects of their choices.

\section{Compensatory Behaviors}

The emergence of $\mathrm{CB}$ is based on individuals believing that a "compensatory behavior" can help them maintain their health. However, people with $\mathrm{CB}$ do not necessarily execute compensatory behaviors. Behavior is only the medium of the belief generated by patients, so compensatory behavior is one of the attributes (Kaklamanou et al., 2013). Simultaneously, compensatory behavior should be distinguished from health behavior, since certain behaviors are indeed compensatory (Lippke, 2014; Fleig et al., 2015), but other compensatory 
TABLE 2 | Articles selected for the final analysis.

\begin{tabular}{|c|c|c|c|c|}
\hline References & Country & Sample size & Research design & Area of focus and contribution of the study \\
\hline Knäuper et al. (2004) & Canada & 634 & Scale development study & $\begin{array}{l}\text { Describes a psychometric scale to measure compensatory health } \\
\text { beliefs and provides data on its reliability and validity. }\end{array}$ \\
\hline Rabiau et al. (2006) & Canada & - & Literature review & $\begin{array}{l}\text { Brings up a model to explain why people create compensatory health } \\
\text { beliefs and how they employ compensatory health beliefs to regulate } \\
\text { their health behaviors. }\end{array}$ \\
\hline de Nooijer et al. (2009) & Netherlands & 145 & Scale testing study & $\begin{array}{l}\text { Culturally adapts compensatory health beliefs scale for use in the Dutch } \\
\text { context and assesses its psychometric properties. }\end{array}$ \\
\hline Rabiau et al. (2009) & Canada & 114 & Scale development study. & $\begin{array}{l}\text { Develops glucose testing compensatory belief scale to investigate } \\
\text { whether compensatory beliefs regarding glucose testing predict blood } \\
\text { glucose levels and adherence to treatment in Canadian adolescents } \\
\text { with type } 1 \text { diabetes. }\end{array}$ \\
\hline Kronick et al. (2011) & Canada & 69 & Longitudinal observational study & $\begin{array}{l}\text { Uses experience sampling methodology to test if, for dieters who face } \\
\text { inevitable temptations over the course of the day, compensatory } \\
\text { thinking is predictive of caloric intake. }\end{array}$ \\
\hline Radtke et al. (2011) & Switzerland & 244 & Scale development study & $\begin{array}{l}\text { Develops a scale to measure smoking-specific compensatory health } \\
\text { beliefs among Switzerland adolescents and to test whether } \\
\text { compensatory health beliefs are related to a lower readiness to stop } \\
\text { smoking. }\end{array}$ \\
\hline Kaklamanou et al. (2013) & England & 43 & Qualitative study & $\begin{array}{l}\text { Utilizes "think aloud" technique in English students to identify the kinds } \\
\text { of difficulties that people experience when completing compensatory } \\
\text { health belief scales and what steps will be required to develop a future } \\
\text { reliable and valid measure of compensatory health beliefs. }\end{array}$ \\
\hline Miquelon et al. (2012) & Canada & 121 & Prospective longitudinal study & $\begin{array}{l}\text { Uses path analysis in Canadian female college students to examine } \\
\text { how initial autonomous motivation would influence compensatory } \\
\text { beliefs activation, goal adherence, and goal attainment over the course } \\
\text { of a diet. }\end{array}$ \\
\hline Radtke et al. (2012) & Switzerland & 385 & $\begin{array}{l}\text { Cross-sectional model verification } \\
\text { study }\end{array}$ & $\begin{array}{l}\text { Investigates the compensatory health beliefs within the model of HAPA } \\
\text { to examine if smoking-specific compensatory health beliefs are able to } \\
\text { add to the prediction of the intention to quit smoking. }\end{array}$ \\
\hline Ernsting et al. (2013) & Germany & 851 & Randomized controlled trial & $\begin{array}{l}\text { Explores how German individual vaccination behavior is affected by the } \\
\text { mediating role of compensatory belief between intention and behavior } \\
\text { through volitional self-regulation strategy intervention. }\end{array}$ \\
\hline Glock et al. (2013) & Luxembourg & 107 & Cross-sectional study & $\begin{array}{l}\text { Investigates implicit and explicit compensatory health beliefs among } \\
\text { German smokers and analyzes their possible influence on healthy } \\
\text { behaviors as well as their role in predicting smoking behavior. }\end{array}$ \\
\hline Poelman et al. (2013) & Netherlands & 179 & Scale development study & $\begin{array}{l}\text { Develops the diet-related compensatory health beliefs scale } \\
\text { (Diet-CHBs) and testing the scale's internal consistency and validity in } \\
\text { Dutchman. }\end{array}$ \\
\hline Berli et al. (2014) & Switzerland & 430 & Prospective cohort study & $\begin{array}{l}\text { Applies multilevel model to examine the contribution of compensatory } \\
\text { health beliefs to the prediction of Swiss adolescents' physical activity } \\
\text { within the model of HAPA. }\end{array}$ \\
\hline Garner et al. (2014) & America & 677 & Cross-sectional study & $\begin{array}{l}\text { Examines whether American students' thinness expectancies } \\
\text { contribute significant variance in the endorsement of excessive exercise } \\
\text { over and above binge eating, restraint, and shape and weight concerns. }\end{array}$ \\
\hline Lippke (2014) & Germany & - & Literature review & $\begin{array}{l}\text { Introduces a new model including compensatory belief, in order to } \\
\text { study multiple behaviors in one model }\end{array}$ \\
\hline Radtke et al. (2014) & Germany & 75 & Randomized controlled trail & $\begin{array}{l}\text { Investigates diet-specific compensatory health beliefs in Switzerland } \\
\text { and England dieting women within the context of the HAPA model to } \\
\text { examine the extent to which diet-specific compensatory health beliefs } \\
\text { contribute to dieting intentions and dietary intake. }\end{array}$ \\
\hline Fleig et al. (2015) & Germany & 416 & Cross-sectional online study & $\begin{array}{l}\text { Using the HAPA model to investigate the extent to which transfer } \\
\text { cognitions and compensatory health beliefs contribute to single } \\
\text { behavior theory in Europeans. }\end{array}$ \\
\hline Amrein et al. (2017) & Switzerland & 232 & Mixed methods study & $\begin{array}{l}\text { Utilizes path models to analyze the role of compensatory health beliefs } \\
\text { within the HAPA model; applies content analysis to investigate the } \\
\text { occurrence of compensatory health beliefs in smartphone chat groups } \\
\text { when pursuing an eating goal to investigate the role of compensatory } \\
\text { health beliefs for two distinct eating behaviors. }\end{array}$ \\
\hline
\end{tabular}


TABLE 2 | Continued

\begin{tabular}{|c|c|c|c|c|}
\hline References & Country & Sample size & Research design & Area of focus and contribution of the study \\
\hline Storm et al. (2017) & Germany & 790 & $\begin{array}{l}\text { Longitudinal randomized controlled } \\
\text { trial }\end{array}$ & $\begin{array}{l}\text { Examines the role of compensatory health beliefs in predicting fruit and } \\
\text { vegetable consumption intentions and actual fruit and vegetable } \\
\text { consumption among German and the Netherlands people. }\end{array}$ \\
\hline Gray et al. (2018) & England & 9 & Qualitative study & $\begin{array}{l}\text { Uses retrospective qualitative process evaluation with one-to-one } \\
\text { semi-structured interviews to explore the mechanisms of physical } \\
\text { activity compensation among Ireland older adults. }\end{array}$ \\
\hline Matley and Davies (2018) & England & 249 & Cross-sectional study & $\begin{array}{l}\text { Conducts an online survey in England to examine associations between } \\
\text { alcohol-specific compensatory health beliefs and behaviors, alcohol } \\
\text { consumption, and alcohol-specific self-efficacy. }\end{array}$ \\
\hline Verger et al. (2018) & France & 19 & Qualitative study & $\begin{array}{l}\text { Conducts semi-structured in-depth interviews of France diabetic } \\
\text { patients to study their reasons for choosing or rejecting seasonal } \\
\text { influenza. Some patients reported their compensatory beliefs. }\end{array}$ \\
\hline Buckley et al. (2019) & Australia & - & Systematic literature review & $\begin{array}{l}\text { Compiles and appraises the evidence of studies pertaining to the } \\
\text { relationship individuals have with food and their bodies after retiring } \\
\text { from sports. }\end{array}$ \\
\hline Capstick et al. (2019) & England & 6,969 & Cross-sectional study & $\begin{array}{l}\text { Develops and evaluates a survey-based instrument to assess people's } \\
\text { compensatory and catalyzing beliefs in Brazil, China, Denmark, India, } \\
\text { Poland, South Africa, and the United Kingdom. }\end{array}$ \\
\hline Dohle and Hofmann (2019) & Germany & 235 & Observational Study & $\begin{array}{l}\text { Explores the relationship between four types of sequential health } \\
\text { behaviors and the health status, life satisfaction, and compensatory } \\
\text { beliefs of French people. }\end{array}$ \\
\hline Martin et al. (2019) & America & 198 & Randomized controlled trail & $\begin{array}{l}\text { Identifies the mechanisms responsible for weight compensation on } \\
\text { American healthy overweight or obese people. }\end{array}$ \\
\hline Petersen et al. (2019) & Australia & 100 & Non-randomized controlled trial & $\begin{array}{l}\text { Tests compensatory health beliefs model by examining the influence of } \\
\text { snack consumption (healthy, unhealthy) on type of activity selected } \\
\text { (physical, sedentary) among Australian female undergraduate students. }\end{array}$ \\
\hline Ren et al. (2019) & China & 64 & Cross-sectional study & $\begin{array}{l}\text { Uses the adapted compensatory health belief scale to make survey, } \\
\text { thus providing behavioral evidence for implicit beliefs and implicit } \\
\text { behavioral tendencies toward smoking-related cues among Chinese } \\
\text { male smokers and non-smokers. }\end{array}$ \\
\hline Sim and Cheon (2019) & Singapore & 23 & Randomized controlled trail & $\begin{array}{l}\text { Investigates the influence of the impending consumption of a meal } \\
\text { perceived to be healthy on prior snack consumption on Singaporeans. }\end{array}$ \\
\hline Amrein et al. (2020) & Switzerland & 166 & Prospective longitudinal study & $\begin{array}{l}\text { Tests whether daily compensatory health beliefs were associated with } \\
\text { the daily intention to quit and daily number of cigarettes smoked during } \\
\text { smoking cessation in Swiss couples. }\end{array}$ \\
\hline Forestier et al. (2020) & France & 104 & Cross-sectional study & $\begin{array}{l}\text { Investigates whether different compensatory health beliefs predict } \\
\text { intentions in individuals with cardiovascular diseases among French } \\
\text { patients. }\end{array}$ \\
\hline Neter and Bagants (2020) & Israel & 773 & $\begin{array}{l}\text { Scale development cross-sectional } \\
\text { study }\end{array}$ & $\begin{array}{l}\text { Develops the compensatory health beliefs on breastfeeding scale. } \\
\text { Attempts to neutralize or reduce the cognitive dissonance between } \\
\text { non-nursing and optimal infant care. }\end{array}$ \\
\hline Amrein et al. (2021) & Switzerland & 45 & Longitudinal observational Study & $\begin{array}{l}\text { Applies an ecological momentary assessment design to distinguish the } \\
\text { effects of state and trait compensatory health beliefs on unhealthy } \\
\text { snack consumption in daily life at the between- and within-person level. }\end{array}$ \\
\hline Law et al. (2021) & Australia & 18 & Qualitative study & $\begin{array}{l}\text { Provides evidence regarding the nature of, and factors underpinning, } \\
\text { Australian parents' physical activity-related compensatory beliefs for } \\
\text { their children. }\end{array}$ \\
\hline Lippke et al. (2021) & Germany & - & Scoping review & $\begin{array}{l}\text { Elaborates on the question as to what extent internet activity is } \\
\text { predictive of psychological well-being based on the Compensatory } \\
\text { Carry-Over Action Model. }\end{array}$ \\
\hline
\end{tabular}

behaviors are detrimental or cannot offset the negative effects of previous unhealthy behaviors (Amrein et al., 2017).

\section{Automatic Motivated Self-Regulatory Process}

Compared with those who do not feel guilty about their harmful diet or smoking habits, individuals who experience $\mathrm{CB}$ do aspire to be healthy-although they may not perform the compensatory behavior later, at intention level, they are attempting to self-regulate (Gray et al., 2018). According to a previous study, the level of CB improves over time after it has been formed because such belief is spontaneously generated and recognized by oneself (Fleig et al., 2015). Under the guidance of others, individuals may also compensate for temptation through subsequent compensatory behavior, but this situation is unstable (Gray et al., 2018). The belief generated under such circumstances cannot be counted as compensatory. 

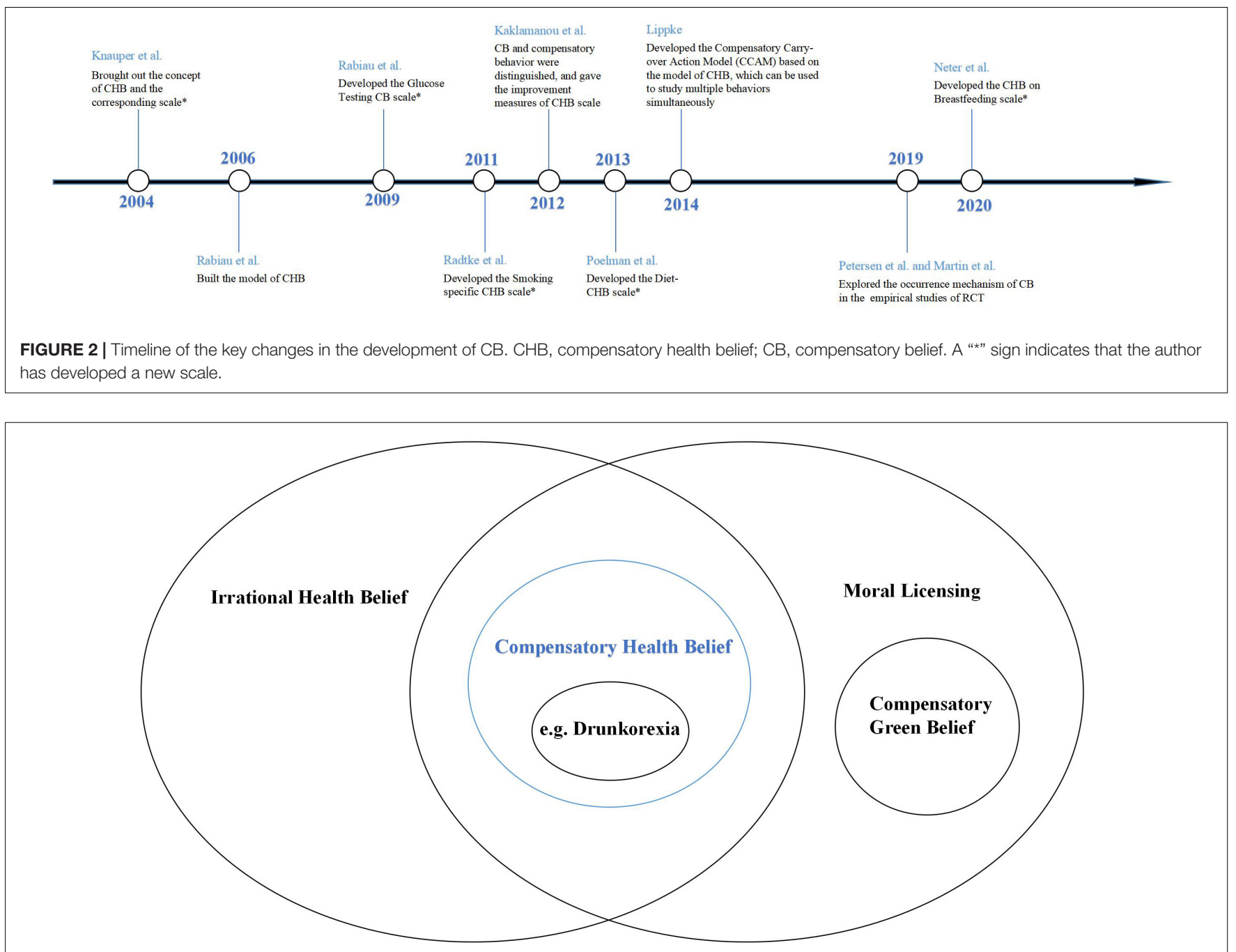

FIGURE 3 | Relationship between CB and the related concepts.

\section{Implicit Cognition}

Implicit cognition means that although the traces of past experiences cannot be self-aware, the previous experiences will potentially impact the current behavior of an individual (Wolsiefer et al., 2017). Basically, the childhood environment of an individual will exert an imperceptible influence on their ideas and cognitions. Studies have confirmed that implicit cognition leads smokers with $\mathrm{CB}$ to associate smoking and exercise behaviors together (Glock et al., 2013; Ren et al., 2019). Thus, implicit cognition is a bridge between unhealthy behavior and later compensatory behavior and promotes the emergence of $\mathrm{CB}$.

\section{Cases of CB}

The theory by Walker and Avant argues that cases can help illuminate and clarify concepts. Therefore, we adapted cases from specific literature into a model case, a borderline case, a related case, and a contrary case.

\section{Model Case}

The model case is a typical example of using a concept to demonstrate all of its defining attributes and to better illustrate the meaning of the main concept.

Max (Rabiau et al., 2009), an 18-year-old patient with diabetes, is aware that he needs to test his blood sugar before sleeping. However, he does not want to test while staying at the house of a friend during the holiday because he is ashamed of sharing with his friends that he has diabetes. Since omitting the test before bedtime is wrong, he feels nervous and anxious (cognitive coping strategies are needed). He has learned that some patients do not measure their blood sugar every day, but he cannot comfortably skip the test (automatic motivated self-regulatory process).

He thinks (implicit cognition) that "if I test my blood sugar twice tomorrow morning, it may compensate for the consequences of omitting it tonight." Max cannot say where this idea originated from, but after strengthening his belief, he goes to bed with peace of mind (pleasure without guilt). The next morning, he tests his blood sugar twice (compensatory behavior) 
at an interval of $2 \mathrm{~h}$. Ultimately, Max often replaces testing before bedtime with double measures the next morning, which will affect his diabetes and overall health.

\section{Borderline Case}

The borderline case is an instance that contains most (but not all) of the defining attributes of the concept.

Daniel (Gray et al., 2018), a 22-year-old undergraduate student who is losing weight, always insists on eating vegetables but seldom exercises. On a certain occasion, his roommate buys fried chicken and invites him to dine together. He wants to enjoy the meal but worries that the interruption of his diet will ruin his previous efforts (cognitive coping strategies). While Daniel is hesitating, his roommate says, "Just eat it. I will go running with you to lose weight later." Then, after Daniel happily enjoys the food (pleasure without guilt), they exercise for an hour that night (compensatory behavior). However, when Daniel passes the fried chicken restaurant again, he forces himself to eat a vegetable salad, but the dissonance of not eating fried chicken afflicts him.

In this case, Daniel does not spontaneously associate fried chicken with sports, which represents an inconformity to the attribute of implicit cognition, as well as being inconsistent with the automatic motivated self-regulatory process. Thus, Daniel did not activate $\mathrm{CB}$.

\section{Related Case}

The related case is an example that is related to the concept but contains only part of the defining attributes of the concept.

Ms. W (Kaklamanou et al., 2013) is a 30-year-old pregnant woman. She gained a significant amount of weight during her pregnancy. One day she wants to drink high-calorie nourishing soup. Although she is prepared to face overweight after pregnancy, eating well still makes her uncomfortable. However, her mother tells her that eating better was good for her baby, so she still has the nourishing soup (pleasure without guilt). This case only reflects the attribute of pleasure without guilt, there is no $\mathrm{CB}$ in Ms. W.

\section{Contrary Case}

The contrary case is a representative example that is clearly different from the concept under study.

Mr. L (Gray et al., 2018) is a 50-year-old retired gymnast. He has maintained healthy eating habits for many years and never compromises on high-calorie foods. At the same time, he enjoys smoking. His friends tell him that smoking does not affect his health and he never feels guilty about smoking. In this case, Mr. L can directly refuse the temptation of high-calorie foods while simultaneously smoking without resistance or hesitation. Consequently, he does not exhibit any CB.

\section{Antecedents and Consequences}

This section extracts the most utilized antecedents and consequences in the included references to further define the characteristics of $\mathrm{CB}$. Identifying antecedents and consequences helps us to have a deeper understanding of the defining attributes.

\section{Antecedents}

The incidents necessary for a concept to exist or happen are called antecedents. Five antecedents of $\mathrm{CB}$ were identified in this analysis: (1) failure to resist desire; (2) reluctance; (3) a conflicting motivational state; (4) seeking appropriate balance; (5) self-image maintenance.

Motivation is the psychological tendency or internal drive that motivates and maintains the action of an individual and directs it to a certain goal (Capstick et al., 2019). For an individual with a health-related goal, whether he is indulging in harmful behaviors or avoiding beneficial ones, these choices will inevitably collide with their goals of pursuing health. In other words, they are in a conflicting motivational state (Rabiau et al., 2006). When they cannot avoid this conflict and struggle with behaviors, they will seek appropriate balance at the motivation level, which leads to $\mathrm{CB}$. Under this circumstance, irresistible situations include the desire to eat high-calorie food, smoke, and drink alcohol (Radtke et al., 2012; Storm et al., 2017; Amrein et al., 2020). The reluctance to engage in healthy actions includes reluctance to exercise and refusing to get vaccinated (Garner et al., 2014; Petersen et al., 2019). In addition, people also attempt to maintain a positive and healthy image, for which $\mathrm{CB}$ becomes a suitable explanation or excuse (Dohle and Hofmann, 2019).

\section{Consequences}

The incidents that occur as a result of the concept are called consequences. Five consequences of $\mathrm{CB}$ were identified in this analysis: (1) lower health-related intentions; (2) justification of unhealthy choices; (3) relief from cognitive dissonance; (4) continued existence of conflict feeling; (5) poor long-term health.

Among these consequences, lower health-related intention and justification of unhealthy choices are frequent in people with CB (Fleig et al., 2015). The activation of CB contributes to finding suitable reasons for individuals to explain "why my unhealthy behavior is not wrong," thus alleviating the discomfort resulting from unhealthy events and eliminating the feelings of compunction or guilt (Berli et al., 2014). Subsequently, the initial discomfort gradually diminishes, until individuals no longer need $\mathrm{CB}$ to alleviate their negative emotions, causing their health intention to decrease in the process (Gray et al., 2018).

The last three consequences are produced under different circumstances, according to the execution of compensatory behaviors. When compensatory behavior is displayed, the cognitive dissonance of an individual can be reduced, leading to relief (Rabiau et al., 2006). Conversely, when compensatory behavior is not carried out, the motivational dissonance of an individual will exist for a given period of time but will be eventually alleviated (Martin et al., 2019). Lastly, compensatory behavior may be implemented, but in some cases, its effects are unhealthy or do not compensate for the previous harmful choices. Therefore, the individual mistakenly thinks that the compensatory behavior eliminates all negative effects, which leads to poor long-term health (Ernsting et al., 2013).

Under the influence of $\mathrm{CB}$, the behavioral patterns of individuals will develop in a negative direction, which explains the impact of CB on poor long-term health. First, CB transforms healthy behaviors that people think they need to do into choices 
that they consider unnecessary. Second, CB encourages people to try unhealthy behaviors and introduce new risk factors into the lifestyle of an individual. Hence, in the absence of $\mathrm{CB}$ management, the above process will be repeated continuously, gradually increasing $\mathrm{CB}$ and its damage to health behavior intention and ending in maintenance of risk behaviors. As long as $\mathrm{CB}$ is not hindered and controlled, the remaining health behaviors will continue to be threatened, and new risk behaviors are likely to form (Petersen et al., 2019). The example mentioned in Section "Model Case" is the typical poor long-term health case caused by CB (Rabiau et al., 2009). CB damages Max's normal behavior with double measures the next morn. Predictably, this weakens his monitoring of diabetes, eventually worsening his health. Based on this explanation, CB poses a great threat to the long-term health of the patients, especially in the field of chronic diseases including obesity and metabolic diseases.

\section{Empirical Referents}

The empirical referents are defined at the end of the analysis and contain measurements of attributes of the concept. The empirical referents of CB have high practical significance since they can help practitioners and caregivers to identify whether a patient has such beliefs or to evaluate the level of CB.

The earliest $\mathrm{CHB}$ scale, which was put forward by Knäuper et al. (2004), has 17 items and is divided into 4 dimensions: eating/sleeping habits, weight regulation, stress, and substance use. In 2012, Kaklamanou et al. (2013) conducted a thinkaloud study where 43 participants completed the $\mathrm{CHB}$ scale while thinking to identify the difficulties people encountered in completing the scale and suggest necessary and practical measures to improve the reliability and validity of the scale. The authors provided the following suggestions: (1) designing items for particular behaviors; (2) clearly informing participants that their own beliefs were being measured rather than those of others; (3) maintaining consistency in the words used throughout the scale to prevent confusion in subjects; and (4) distinguishing the measurement of CB and behavior.

Since then, many scholars have adapted and tested the CHB scale under different situations. In the field of weight management, Poelman et al. (2013) developed the dietrelated $\mathrm{CHB}$ (Diet-CHB) scale, which included more specific descriptions of the type and quantity of foods. They reported three factors associated with diet, including exercise, food portions, and front-of-package labeling. Their findings revealed a significant association between Diet-CHB scale and CHB scale, likely indicative of similarities in $\mathrm{CB}$ among people in the field of weight management. Furthermore, Diet-CHB scale also obtained the ideal reliability and validity in the verification.

For other health-related behaviors, researchers have developed various scales based on the $\mathrm{CHB}$ scale. For instance, Rabiau et al. (2009) developed a glucose testing CB scale with six items. Some adolescents with diabetes with this belief do not adhere to glucose testing and consider that taking other measures (such as eating healthier) can compensate. Therefore, this scale has been adopted to evaluate teenagers, which can help nurses monitor those who are potentially disinclined to conduct self-glucose monitoring. The score of the scale can also guide clinicians or psychologists to better adjust the therapeutic regimen of their patient. Radtke et al. (2011) designed a smoking-specific CHB scale, which has been shown to have high reliability and validity. Their results further suggested that a smokingspecific $\mathrm{CHB}$ scale is an effective tool to assess the readiness of adolescents to stop smoking. Additionally, smoking-specific $\mathrm{CHB}$ scale highly correlated with $\mathrm{CHB}$ scale, since all its items covered various compensatory strategies. In a recent study, Neter and Bagants (2020) developed the CHBs on the breastfeeding (CHB$\mathrm{BF})$ scale. Their work extends $\mathrm{CB}$ research onto breastfeeding health-related behavior studies. Many women find breastfeeding challenging, and $\mathrm{CB}$ helps them escape this cognitive conflict by rationalizing their avoiding breastfeeding. Identifying women with potentially negative attitudes toward breastfeeding using CHB-BF can help to correct their misconceptions in the early postpartum period.

\section{Conceptualization of CB}

This study identified that there are various definitions of $\mathrm{CB}$ in the context of health behaviors and that these definitions need to be more precise. After analyzing the existing literature, we propose a final, clarified, and refined definition. CB is:

A belief that the negative effects of participating in unhealthy behaviors or evading healthy behaviors can be offset by the positive effects of another behavior that the subject believes to be beneficial, thus relieving the inner unease of an individual.

Figure 4 shows a conceptual model covering the relationship between attributes, antecedents, and consequences of $\mathrm{CB}$ on the theoretical level.

\section{DISCUSSION}

Our study aimed to generate a clarified definition of $\mathrm{CB}$ for the management of unhealthy behaviors and to facilitate further interventions for people with such beliefs. CB is characterized by five attributes: cognitive coping strategy, pleasure without guilt, compensatory behaviors, automatic motivated self-regulatory process, and implicit cognition. Clinicians and caregivers can identify patients who have $\mathrm{CB}$ by the abovementioned attributes and implement measures to strengthen the management of these patients.

According to our review, it is evident that, in most cases, the activation of $\mathrm{CB}$ will have negative effects on the health-related behaviors of the people; hence, developing effective coping strategies that target $\mathrm{CB}$ is essential. Although no studies have specifically focused on interventions for negative $\mathrm{CB}$, researchers have offered some recommendations. First, we should promote awareness of their tendency to form such beliefs in individuals with CB (Ernsting et al., 2013) and let them realize these beliefs need to be combined with the execution of behaviors to be effective (Radtke et al., 2011). Second, we can use strategies like cognitive behavioral therapy (CBT) to reconstruct cognitive dissonance (Kronick et al., 2011). In this process, practitioners should help subjects feel responsible for their actions and able to control them (Knäuper et al., 2004). Third, health 


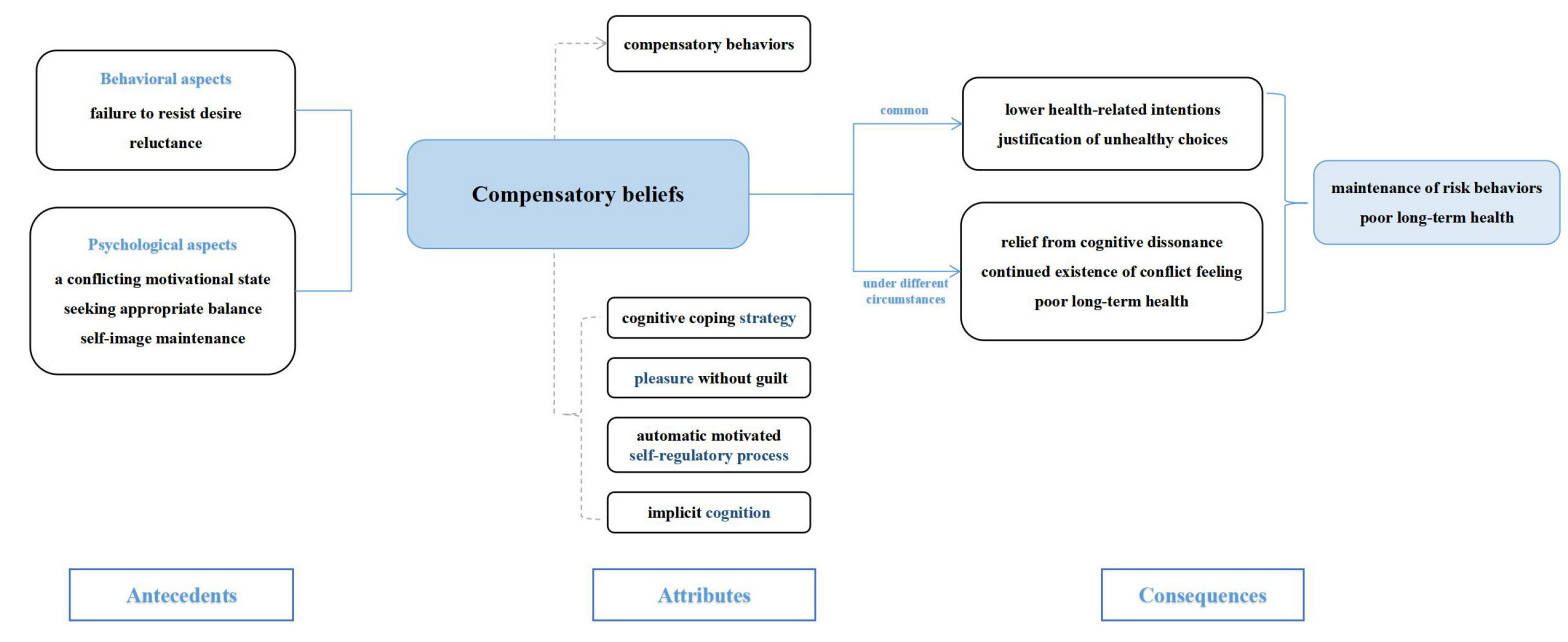

FIGURE 4 | Proposed conceptual model of CB.

education targeted compensatory behaviors would be useful for patients to fully realize the detrimental effects of unhealthy behaviors (Forestier et al., 2020). Fourth, steps should be taken to strengthen time management in those with higher CB levels, such as setting a specific compensatory behavior implementation plan and keeping a diary of compensatory behavior completion (Gray et al., 2018).

According to a few other scholars, CB may play a positive role in the cases of individuals with extremely deficient selfcontrol. Amrein et al. found CB is more effective in promoting compensatory behavior than in giving up unhealthy behavior (Amrein et al., 2017). Based on CB, one can first promote the formation of compensatory behavior, then quit harmful behaviors. Similarly, Gray et al. (2018) also observed that, for people who cannot resist temptations at all, promoting $\mathrm{CB}$ may help them facilitate healthy behaviors. However, these recommendations of using $\mathrm{CB}$ to promote healthy behavior are controversial, as many studies have demonstrated a negative relationship between $\mathrm{CB}$ and behavioral motivation (Radtke et al., 2014; Forestier et al., 2020).

This conceptual analysis is of great importance for medical work. Clinicians and caregivers should be aware of the obstruction of $\mathrm{CB}$ to the implementation of health behaviors due to its severe negative effects on the medical adherence of patients (Capstick et al., 2019). Our review comprehensively analyzed the concept of $\mathrm{CB}$, which is conducive to a better understanding of the concept and to identify people with $\mathrm{CB}$ by the attributes and antecedents we have described. In addition, our review summarized the development history, the existing literature, and the tools for $\mathrm{CB}$ evaluation in the past two decades. Taken together, this information can aid researchers interested in CB in learning in which areas there is sufficient empirical evidence of $\mathrm{CB}$ and which areas lack in-depth research on health-related CB.

The novelty in our study lies in that we are the first to analyze the important concept of $\mathrm{CB}$ with the method of concept analysis. Our review is also a summary of the studies on CB. The literature information table and timeline diagram summarize well the development of $\mathrm{CB}$ in recent years. Most importantly, updating the attributes, antecedents, and consequences will bring a new perspective to future research of $\mathrm{CB}$. Our findings make a valuable contribution to better defining and understanding the concept of $\mathrm{CB}$.

Finally, several limitations to this analysis need to be acknowledged. First, empirical studies that explore mechanisms of compensation in health behaviors are lacking. Martin et al. and Petersen et al. were the first to attempt to clarify the mechanism of compensation in weight management (Martin et al., 2019; Petersen et al., 2019). They directly observed the behavioral choices of subjects under the activation of $\mathrm{CB}$ in an experimental scenario and their findings corroborate our current knowledge of CB. However, these two studies were focused on diet and exercise behaviors. Therefore, the mechanisms obtained do not apply to the entirety of health management. Second, this review is limited to the field of health behavior management, even though, according to the search results, $\mathrm{CB}$ has been reported in other areas as well. For instance, drivers may think: "as long as I slow down, it will be safe to use the cell phone while driving" (Zhou et al., 2016), while environmental managers may think that "it's OK to cut down trees occasionally as I have been working on projects to improve the ecosystem" (Sörqvist and Langeborg, 2019). Hence, an increasing number of studies have confirmed the existence of $\mathrm{CB}$ in the field of health management and other fields. Third, since we only analyzed CB in an English context, a language bias may exist and other language backgrounds should be investigated. In addition, most of the studies we included came from Europe and North America, as we did not find enough $\mathrm{CB}$ studies from developing countries. Therefore, studying $\mathrm{CB}$ in different social contexts is also necessary because socioeconomic conditions can greatly influence the behaviors of the people.

To explore the mechanisms of $\mathrm{CB}$ in greater detail, more influencing factors should be included in future research and practice, and the action path should be discussed or verified based on various theoretical models. Furthermore, researchers need to distinguish between $\mathrm{CB}$ and compensatory behaviors because 
beliefs and behaviors are different dimensions. We recommend focusing on beliefs, because only when the CB is corrected can people sustain healthy behaviors and avoid the maintenance of risk behaviors in the long term. It is necessary to promote positive behavioral change by taking certain interventions that correct false beliefs. In addition, the opposite compensatory effects between behaviors should be taken into account, since individuals may take advantage of their active participation in healthy behaviors to prove that they can engage in unhealthy behaviors (Amrein et al., 2020). Finally, keeping a watchful eye on the potential emotions and cognition in compensatory behavior and paying attention to their distinctions is paramount. This will enable identifying between exercising due to dissatisfaction with body image (Nolan and Eshleman, 2016) from exercising due to eating disorders. Overall, future research on $\mathrm{CB}$ should be more detailed and consider $\mathrm{CB}$ in different contexts.

\section{CONCLUSION}

Compensatory belief is one of the principal psychological variables in the health-related behavior management of the patients. The identification, assessment, and regulation of this belief are important for medical work. CB stems from motivational dissonance or confliction. It provides feelings of relief and pleasure but has negative effects on long-term health. The attributes, antecedents, consequences, empirical references, and definitions of $\mathrm{CB}$ that were identified in this study can

\section{REFERENCES}

Amrein, M. A., Lüscher, J., Berli, C., Radtke, T., and Scholz, U. (2020). Do daily compensatory health beliefs predict intention to quit and smoking behavior? A daily diary study during smoking cessation. Int. J. Environ. Res. Public Health 17:6419. doi: 10.3390/ijerph17176419

Amrein, M. A., Rackow, P., Inauen, J., Radtke, T., and Scholz, U. (2017). The role of compensatory health beliefs in eating behavior change: a mixed method study. Appetite 116, 1-10. doi: 10.1016/j.appet.2017.04.016

Amrein, M. A., Scholz, U., and Inauen, J. (2021). Compensatory health beliefs and unhealthy snack consumption in daily life. Appetite 157:104996. doi: 10.1016/j. appet.2020.104996

Berli, C., Loretini, P., Radtke, T., Hornung, R., and Scholz, U. (2014). Predicting physical activity in adolescents: the role of compensatory health beliefs within the Health Action Process Approach. Psychol. Health 29, 458-474. doi: 10.1080/ 08870446.2013.865028

Blanton, H., and Gerrard, M. (1997). Effect of sexual motivation on men's risk perception for sexually transmitted disease: there must be 50 ways to justify a lover. Health Psychol. 16, 374-379. doi: 10.1037//0278-6133.16.4.374

Buckley, G. L., Hall, L. E., Lassemillante, A. M., Ackerman, K. E., and Belski, R. (2019). Retired athletes and the intersection of food and body: a systematic literature review exploring compensatory behaviours and body change. Nutrients 11:1395. doi: 10.3390/nu11061395

Capstick, S., Whitmarsh, L., Nash, N., Haggar, P., and Lord, J. (2019). Compensatory and catalyzing beliefs: their relationship to pro-environmental behavior and behavioral spillover in seven countries. Front. Psychol. 10:963. doi: 10.3389/fpsyg.2019.00963

Choquette, E. M., Ordaz, D. L., Melioli, T., Delage, B., Chabrol, H., Rodgers, R., et al. (2018). Food and Alcohol Disturbance (FAD) in the U.S. and France: Nationality and gender effects and relations to drive for thinness and alcohol use. Eat. Behav. 31, 113-119. doi: 10.1016/j.eatbeh.2018.09.002

Christensen, A. J., Moran, P. J., and Wiebe, J. S. (1999). Assessment of irrational health beliefs: relation to health practices and medical regimen adherence. Health Psychol. 18, 169-176. doi: 10.1037//0278-6133.18.2.169 help clinicians and caregivers to develop interventions for $\mathrm{CB}$ regulation based on theories, as well as to measure the level of $\mathrm{CB}$ in the context of health behaviors management. This concept analysis provides valuable insights that can be used in medical practice, research, education, and management.

\section{AUTHOR CONTRIBUTIONS}

KZ and QX: study design. KZ: data acquisition and analysis. KZ, QX, HZ, and XX: manuscript preparation. All authors contributed to the article and approved the submitted version.

\section{FUNDING}

This work was supported by the Project "The exploration of trajectories and intervention program of frailty for gastric cancer survivors based on the health ecology theory" supported by National Natural Science Foundation of China [grant number 82073407]; the Project of "Design of intervention project for health behavior change of bariatric patients based on CCAM model" funded by the Postgraduate Research \& Practice Innovation Program of Jiangsu Province [grant number KYCX20_1446]; and the Priority Discipline Development Program of Jiangsu Higher Education Institutions, General Office, the People Government of Jiangsu Province [grant number 2018. 87].

de Nooijer, J., Puijk-Hekman, S., and van Assema, P. (2009). The compensatory health beliefs scale: psychometric properties of a cross-culturally adapted scale for use in The Netherlands. Health Educ. Res. 24, 811-817. doi: 10.1093/her/ cyp016

Dohle, S., and Hofmann, W. (2019). Consistency and balancing in everyday health behaviour: an ecological momentary assessment approach. Appl. Psychol. Health Well Being 11, 148-169. doi: 10.1111/aphw.12148

Ernsting, A., Schwarzer, R., Lippke, S., and Schneider, M. (2013). 'I do not need a flu shot because I lead a healthy lifestyle': compensatory health beliefs make vaccination less likely. J. Health Psychol. 18, 825-836. doi: 10.1177/ 1359105312455076

Fleig, L., Ngo, J., Roman, B., Ntzani, E., Satta, P., Warner, L. M., et al. (2015). Beyond single behaviour theory: adding cross-behaviour cognitions to the health action process approach. Br. J. Health Psychol. 20, 824-841. doi: 10.1111/ bjhp. 12144

Forestier, C., Sarrazin, P., Sniehotta, F., Allenet, B., Heuzé, J. P., Gauchet, A., et al. (2020). Do compensatory health beliefs predict behavioural intention in a multiple health behaviour change context? Evidence in individuals with cardiovascular diseases? Psychol. Health Med. 25, 593-600. doi: 10.1080/ 13548506.2019.1653476

Garner, A., Davis-Becker, K., and Fischer, S. (2014). An exploration of the influence of thinness expectancies and eating pathology on compensatory exercise. Eat. Behav. 15, 335-338. doi: 10.1016/j.eatbeh.2014.04.017

Glock, S., Müller, B. C., and Krolak-Schwerdt, S. (2013). Implicit associations and compensatory health beliefs in smokers: exploring their role for behaviour and their change through warning labels. Br. J. Health Psychol. 18, 814-826. doi: 10.1111/bjhp.12023

Gray, P., Murphy, M., Gallagher, A., and Simpson, E. (2018). A qualitative investigation of physical activity compensation among older adults. Br. J. Health Psychol. 23, 208-224. doi: 10.1111/bjhp.12282

Hart, E. A. (1993). The Effect of Planned Exercise as a Disinhibitor of Dietary Restraint: An Investigation of Perceived Control and Resultant Affect. Dissertation submitted to the faculty of the Graduate School at the University of North Carolina at Greensboro. Greensboro: University of North Carolina. 
Hofmann, W., Wisneski, D. C., Brandt, M. J., and Skitka, L. J. (2014). Morality in everyday life. Science (New York, N.Y.) 345, 1340-1343. doi: 10.1126/science. 1251560

Kaklamanou, D., Armitage, C. J., and Jones, C. R. (2013). A further look into compensatory health beliefs: a think aloud study. Br. J. Health Psychol. 18, 139-154. doi: 10.1111/j.2044-8287.2012.02097.x

Knäuper, B., Rabiau, M. A., Cohen, O., and Patriciu, N. (2004). Compensatory health beliefs: scale development and psychometric properties. Psychol. Health 19, 607-624. doi: 10.1080/0887044042000196737

Kouchaki, M. (2011). Vicarious moral licensing: the influence of others' past moral actions on moral behavior. J. Pers. Soc. Psychol. 101, 702-715. doi: 10.1037/ a0024552

Kronick, I., Auerbach, R. P., Stich, C., and Knäuper, B. (2011). Compensatory beliefs and intentions contribute to the prediction of caloric intake in dieters. Appetite 57, 435-438. doi: 10.1016/j.appet.2011.05.306

Law, K. H., Dimmock, J. A., Thornton, A. L., Nicholas, J. C., Ho, G., Gucciardi, D. F., et al. (2021). 'They deserve a treat': the nature and antecedents of parental licensing surrounding children's physical activity. Public Health Nutr. 24, 2098-2108. doi: 10.1017/S1368980020002554

Lippke, S. (2014). Modelling and supporting complex behavior change related to obesity and diabetes prevention and management with the compensatory carry-over action model. J. Diabetes Obes. 1, 39-43. doi: 10.15436/2376-0494. 14.009

Lippke, S., Dahmen, A., Gao, L., Guza, E., and Nigg, C. R. (2021). To what extent is internet activity predictive of psychological well-being? Psychol. Res. Behav. Manag. 14, 207-219. doi: 10.2147/PRBM.S274502

Martin, C. K., Johnson, W. D., Myers, C. A., Apolzan, J. W., Earnest, C. P., Thomas, D. M., et al. (2019). Effect of different doses of supervised exercise on food intake, metabolism, and non-exercise physical activity: the E-MECHANIC randomized controlled trial. Am. J. Clin. Nutr. 110, 583-592. doi: 10.1093/ajcn/ nqz054

Matley, F., and Davies, E. L. (2018). Resisting temptation: alcohol specific selfefficacy mediates the impacts of compensatory health beliefs and behaviours on alcohol consumption. Psychol. Health Med. 23, 259-269. doi: 10.1080/13548506. 2017.1363395

McGinnis, J. M., and Foege, W. H. (1993). Actual causes of death in the United States. JAMA 270, 2207-2212. doi: 10.1001/jama.1993.03510180077038

Miquelon, P., Knäuper, B., and Vallerand, R. J. (2012). Motivation and goal attainment. The role of compensatory beliefs. Appetite 58, 608-615. doi: 10. 1016/j.appet.2011.12.025

Monin, B., and Miller, D. T. (2001). Moral credentials and the expression of prejudice. J. Pers. Soc. Psychol. 81, 33-43. doi: 10.1037/0022-3514.81.1.33

Neter, E., and Bagants, L. (2020). Compensatory health beliefs on breastfeeding varying by breastfeeding status; a scale development. Int. J. Environ. Res. Public Health 17:5759. doi: 10.3390/ijerph17165759

NIH (1992). Methods for voluntary weight loss and control. NIH Technology Assessment Conference Panel. Ann. Intern. Med. 116, 942-949. doi: 10.7326/ 0003-4819-116-11-942

NIH (1993). Very low-calorie diets. National task force on the prevention and treatment of obesity, national institutes of health. JAMA 270, 967-974. doi: 10.1001/jama.1993.03510080071034

Nolan, L. J., and Eshleman, A. (2016). Paved with good intentions: paradoxical eating responses to weight stigma. Appetite 102, 15-24. doi: 10.1016/j.appet. 2016.01.027

Petersen, J. M., Prichard, I., Kemps, E., and Tiggemann, M. (2019). The effect of snack consumption on physical activity: a test of the compensatory health beliefs model. Appetite 141:104342. doi: 10.1016/j.appet.2019. 104342

Pinel, J. P., Assanand, S., and Lehman, D. R. (2000). Hunger, eating, and ill health. Am. Psychol. 55, 1105-1116. doi: 10.1037//0003-066x.55.10.1105

Poelman, M. P., Vermeer, W. M., Vyth, E. L., and Steenhuis, I. H. (2013). 'I don't have to go to the gym because I ate very healthy today': the development of a scale to assess diet-related compensatory health beliefs. Public Health Nutr. 16, 267-273. doi: 10.1017/S1368980012002650

Prochaska, J. J., and Prochaska, J. O. (2011). A review of multiple health behavior change interventions for primary prevention. Am. J. Lifestyle Med. 5, 208-222. doi: $10.1177 / 1559827610391883$
Rabiau, M. A., Knäuper, B., and Miquelon, P. (2006). The eternal quest for optimal balance between maximizing pleasure and minimizing harm: the compensatory health beliefs model. Br. J. Health Psychol. 11(Pt 1), 139-153. doi: 10.1348/ $135910705 X 52237$

Rabiau, M. A., Knäuper, B., Nguyen, T. K., Sufrategui, M., and Polychronakos, C. (2009). Compensatory beliefs about glucose testing are associated with low adherence to treatment and poor metabolic control in adolescents with type 1 diabetes. Health Educ. Res. 24, 890-896. doi: 10.1093/her/cyp032

Radtke, T., Kaklamanou, D., Scholz, U., Hornung, R., and Armitage, C. J. (2014). Are diet-specific compensatory health beliefs predictive of dieting intentions and behaviour? Appetite 76, 36-43. doi: 10.1016/j.appet.2014.01.014

Radtke, T., Scholz, U., Keller, R., and Hornung, R. (2012). Smoking is ok as long as I eat healthily: compensatory Health Beliefs and their role for intentions and smoking within the Health Action Process Approach. Psychol. Health 27(Suppl. 2), 91-107. doi: 10.1080/08870446.2011.603422

Radtke, T., Scholz, U., Keller, R., Knäuper, B., and Hornung, R. (2011). Smokingspecific compensatory health beliefs and the readiness to stop smoking in adolescents. Br. J. Health Psychol. 16, 610-625. doi: 10.1348/2044-8287.002001

Ren, L., Cui, L. B., Chen, C., Dong, X., Wu, Z., Wang, Y., et al. (2019). The implicit beliefs and implicit behavioral tendencies towards smoking-related cues among Chinese male smokers and non-smokers. BMC Public Health 19:1000. doi: 10.1186/s12889-019-7319-7

Schachter, S. (1982). Recidivism and self-cure of smoking and obesity. Am. Psychol. 37, 436-444. doi: 10.1037//0003-066x.37.4.436

Schifter, D. E., and Ajzen, I. (1985). Intention, perceived control, and weight loss: an application of the theory of planned behavior. J. Pers. Soc. Psychol. 49, 843-851. doi: $10.1037 / / 0022-3514.49 .3 .843$

Sim, A. Y., and Cheon, B. K. (2019). Influence of impending healthy food consumption on snacking: nudging vs. compensatory behaviour. Physiol. Behav. 198, 48-56. doi: 10.1016/j.physbeh.2018.10.010

Sörqvist, P., and Langeborg, L. (2019). Why people harm the environment although they try to treat it well: an evolutionary-cognitive perspective on climate compensation. Front. Psychol. 10:348. doi: 10.3389/fpsyg.2019.00348

Storm, V., Reinwand, D., Wienert, J., Kuhlmann, T., De Vries, H., and Lippke, S. (2017). Brief report: compensatory health beliefs are negatively associated with intentions for regular fruit and vegetable consumption when self-efficacy is low. J. Health Psychol. 22, 1094-1100. doi: 10.1177/1359105315625358

Verger, P., Bocquier, A., Vergélys, C., Ward, J., and Peretti-Watel, P. (2018). Flu vaccination among patients with diabetes: motives, perceptions, trust, and risk culture - a qualitative survey. BMC Public Health 18:569. doi: 10.1186/s12889018-5441-6

Walker, L. O., and Avant, K. C. (2014). "Concept analysis," in Strategies for Theory Construction in Nursing, 5th Edn, eds L. O. Walker and K. C. Avant (London: Pearson).

Wolsiefer, K., Westfall, J., and Judd, C. M. (2017). Modeling stimulus variation in three common implicit attitude tasks. Behav. Res. Methods 49, 1193-1209. doi: 10.3758/s13428-016-0779-0

Zhou, R., Yu, M., and Wang, X. (2016). Why do drivers use mobile phones while driving? The contribution of compensatory beliefs. PLoS One 11:e0160288. doi: $10.1371 /$ journal.pone. 0160288

Conflict of Interest: The authors declare that the research was conducted in the absence of any commercial or financial relationships that could be construed as a potential conflict of interest.

Publisher's Note: All claims expressed in this article are solely those of the authors and do not necessarily represent those of their affiliated organizations, or those of the publisher, the editors and the reviewers. Any product that may be evaluated in this article, or claim that may be made by its manufacturer, is not guaranteed or endorsed by the publisher.

Copyright $\odot 2021 \mathrm{Zhao}, \mathrm{Xu}, \mathrm{Zhu}$ and $\mathrm{Xu}$. This is an open-access article distributed under the terms of the Creative Commons Attribution License (CC BY). The use, distribution or reproduction in other forums is permitted, provided the original author(s) and the copyright owner(s) are credited and that the original publication in this journal is cited, in accordance with accepted academic practice. No use, distribution or reproduction is permitted which does not comply with these terms. 